\title{
PERDAS DE SOLO, ÁGUA E NUTRIENTES POR EROSÃO HÍDRICA EM UMA ESTRADA FLORESTAL NA SERRA CATARINENSE
}

\author{
SOIL, WATER AND NUTRIENT LOSSES PROCEEDED BY WATER EROSION IN A FORESTRY \\ ROAD IN SANTA CATARINA STATE, BRAZIL
}

\author{
Luciane Costa de Oliveira $^{1} \quad$ Ildegardis Bertol ${ }^{2}$ Fabrício Tondello Barbosa $^{3} \quad$ Mari Lucia Campos $^{4}$ \\ José Mecabô Junior ${ }^{5}$
}

\section{RESUMO}

O uso do solo influencia a erosão hídrica, sendo que, em geral, em estradas dentro de áreas reflorestais são altas as perdas de solo, água e elementos químicos. O trabalho objetivou quantificar as perdas de solo, água e elementos químicos causadas pela erosão hídrica durante 17 meses, sob chuva natural, em uma estrada dentro de uma área de reflorestamento de pinus. O estudo foi realizado no município de Campo Belo do Sul - SC, na Florestal Gateados Ltda., em um solo Nitossolo Háplico típico. Para a coleta da água e do solo, foi utilizada a Roda Coshocton. As perdas de solo foram de 19,65 t ha-1 enquanto as perdas de água equivaleram a $37 \%$ do volume de chuva precipitado no período experimental. Houve correlação linear e positiva entre altura de chuva e perdas de água por escoamento superficial, entre altura de chuva e perdas de solo por erosão, e entre perdas de solo e perdas de água por erosão hídrica. Os teores dos elementos químicos estudados em geral foram altos nos sedimentos da erosão hídrica, superiores aos teores encontrados na camada superficial do solo na qual a erosão se originou e muito superiores aos encontrados na água da enxurrada. Portanto, para sistemas de exploração do solo em que as perdas de sedimentos são altas, como é o caso de estradas florestais, as perdas de nutrientes causadas pela erosão hídrica estão mais relacionadas às perdas de sedimentos do que às perdas de água.

Palavras-chave: erosão hídrica; Roda Coshocton; estrada florestal.

\section{ABSTRACT}

The land use influences erosion, and in general, on roads in reforested areas, soil, water and chemical element losses are high. This study had as objective to quantify soil, water and nutrient losses proceeded by erosion during 17 months, on natural rain, on a road in an area of pine reforestation. The study was performed in Campo Belo do Sul,/SC state, Florestal Gateados Ltda, in a typical 'Nitossolo Háplico'. Water and soil samples were obtained with the use of a Coshocton wheel. Soil loss reached $19.65 \mathrm{t} \mathrm{ha}^{-1}$ while water loss was equivalent to $37 \%$ of the rainfall during the experiment. There was a linear and positive correlation between rainfall height and water loss by run-off, between rainfall height and soil loss by erosion, and

1 Engenheira Agrônoma, Dra ${ }^{\mathrm{a}}$, Instituto Federal de Educação de Santa Catarina, Campus Lages, Rua Heitor Villa Lobos, 222, Bairro São Francisco, CEP 88506-400, Lages (SC), Brasil. luciane.costa@ifsc.edu.br

2 Engenheiro Agrônomo, Dr., Departamento de Solos e Recursos Naturais, Universidade do Estado de Santa Catarina, Av. Luiz de Camões, 2090, CEP 88520-000, Lages (SC), Brasil. a2ib@cav.udesc.br

3 Engenheiro Agrônomo, Dr., Departamento de Solos e Recursos Naturais, Universidade do Estado de Santa Catarina, Av. Luiz de Camões, 2090, CEP 88520-000, Lages (SC), Brasil. a2ftb@cav.udesc.br

4 Engenheira Agrônoma, Dr ${ }^{\mathrm{a}}$., Departamento de Solos e Recursos Naturais,

Universidade do Estado de Santa Catarina, Av. Luiz de Camões, 2090, CEP 88520-000, Lages (SC), Brasil. a2mlc@cav.udesc.br

5 Engenheiro Agrônomo, Msc., Instituto Federal de Educação de Santa Catarina, Campus

Lages, Rua Heitor Villa Lobos, 222, Bairro São Francisco, CEP 88506-400, Lages (SC), Brasil. jose.mecabo@ifsc.edu.br

Recebido para publicação em 3/12/2012 e aceito em 2/10/2013 
between soil loss and water loss by water erosion. The contents of the chemical elements studied were high, in general, in sediments of water erosion, superior to the content found on the topsoil from where erosion had origin, and much superior to those ones found on runoff. So, for systems of land use where the sediment loss is high, as for forestry roads, losses of nutrients caused by water erosion are more related to sediment loss than water loss.

Keywords: soil erosion; Coshocton wheel;forest roads.

\section{INTRODUÇÃO}

No cultivo de florestas, o preparo do solo por métodos não conservacionistas, como a abertura de sulcos na direção da pendente do terreno e com revolvimento do solo, é uma operação de manejo que acelera a erosão hídrica, em especial nos períodos de ocorrência de altas precipitações pluviométricas (CAVICHIOLO, 2005). O fenômeno decorrente da aceleração da erosão também pode ocorrer na colheita da floresta, quando mecanizada e realizada de forma inadequada, devido à redução da cobertura superficial e ao aumento da compactação do solo. Em especial, a inadequada locação da rede viária em relação às cotas do relevo, resulta em sérios problemas de erosão hídrica devido à captação e condução de água no leito das vias e consequente entrada de enxurrada concentrada em áreas fragilizadas nas cotas mais baixas do terreno. Nessas condições, a erosão superficial, principalmente em sulcos, pode evoluir para a formação de voçorocas, na própria estrada ou em talhões adjacentes, segundo Cavichiolo (2005). Em relação à rede viária para uso florestal, geralmente há um ineficiente sistema de drenagem associado à inexistência de controle e prevenção da erosão nas estradas. Ao serem submetidas ao tráfego pesado de máquinas e composições veiculares de carga, durante as operações de colheita e transporte de madeira, o escoamento superficial acelera-se no leito da estrada e, consequentemente, ocorrem o assoreamento e a poluição de mananciais (CAMARGO CORRÊA, 2005).

No cultivo de florestas, Neary e Hornbeck (1994) estimaram que mais de $90 \%$ dos sedimentos de erosão eram provenientes das estradas destinadas à colheita, já que nelas a interceptação de água da chuva é nula. Os autores observaram que nessas estradas a taxa de erosão era aumentada em quatro vezes, enquanto na fase de construção de estradas, dentro da área de exploração da floresta, essa diferença poderia chegar a 120 vezes, mesmo em áreas não perturbadas, mas com elevado declive.
Disso depreende-se que as estradas apresentam o maior efeito impactante na erosão hídrica em relação ao restante da área cultivada, especialmente durante a fase de colheita da floresta (SOUZA et al., 2001). Christopher (2002) observou que as maiores perdas de solo ocorriam durante e imediatamente após a construção das estradas, devido à instabilidade do solo e aos distúrbios causados no terreno pela passagem de caminhões e equipamentos. $\mathrm{Na}$ ausência ou em condições de inadequado dimensionamento de revestimento do leito da estrada e com ineficiente sistema de drenagem, diminui a permeabilidade do solo e aumenta o escoamento superficial, propiciando o aumento de erosão, principalmente quando se trata de condições de maior declividade, comum em áreas florestais (CAMARGO CORRÊA et al., 2009).

As estradas em florestas cultivadas em geral são submetidas a tráfego leve, às vezes temporário. O tráfego pesado e muito pesado, quando ocorre normalmente é em sentido único, ocasionado geralmente por meio de veículos com capacidade de carga entre 30 e 40 toneladas e, às vezes, acima de 40 toneladas. Nos últimos anos, aumentou a necessidade dessas estradas nas florestas cultivadas, devido ao aumento do volume de tráfego de veículos de alta tonelagem, aumento das distâncias de transporte em rodovias de baixa qualidade, devido à necessidade de trafegabilidade durante todo o ano e de estradas com maior vida útil (CAMARGO CORRÊA et al., 2009). Uma estrada florestal de boa qualidade, do ponto de vista de trafegabilidade e de controle da erosão, sob condição de tráfego pesado, deve apresentar várias características, tais como: inclinação lateral de aproximadamente $7 \%$, do centro para as laterais, de forma a abaular o leito, para conduzir a enxurrada para locais distantes da estrada até drenos ou áreas revestidas com vegetação densa; alto raio hidráulico e superfície rugosa; mínima quantidade de sedimentos soltos na superfície e disponíveis para o transporte pela enxurrada; restos culturais ou outras formas de cobertura do solo nos canais, dispostos de forma 
intercalada e no sentido transversal ao relevo; presença de pontes e/ou bueiros para a passagem do fluxo de água de um lado para outro da estrada; maior proporção possível de estradas cascalhadas; um programa regular de manutenção nos períodos de chuvas não erosivas; uma zona de proteção do curso de água adjacente ao fluxo dos drenos das estradas. A estrada florestal influencia negativamente alguns processos hidrológicos em áreas com declive. Isto ocorre por receber diretamente a água da chuva na superfície, sem interceptação, por iniciar a enxurrada quase que imediatamente após o início da chuva devido à forte compactação do solo, por concentrar o escoamento superficial, em vez de dividi-lo, sobre o leito e, principalmente, nos canais de drenagem adjacentes (CHRISTOPHER, 2002).

A ocorrência de erosão hídrica em estradas de uso florestal, segundo Camargo Corrêa (2009), é responsável por $99,7 \%$ das perdas totais de solo que ocorrem na floresta como um todo. Isto evidencia a importância de um adequado planejamento de estradas nessas áreas, de maneira a atender às necessidades da propriedade, mas com a menor densidade possível, a fim de minimizar a ocorrência de erosão. Dessa forma, o objetivo do presente trabalho foi quantificar as perdas de solo, água e produtos químicos dentre eles nutrientes de plantas, provenientes de uma estrada de uso florestal, sob chuva natural.

\section{MATERIAL E MÉTODO}

O trabalho foi realizado em campo, na empresa Florestal Gateados Ltda., situada no município de Campo Belo do Sul - SC, localizada a $67 \mathrm{~km}$ do município de Lages, durante o período de setembro de 2009 a janeiro de 2011. O clima da região é mesotérmico úmido, classificado como $\mathrm{Cfb}$, segundo Köppen (1948), com temperatura variando de 13 a $25^{\circ} \mathrm{C}$ e com chuvas distribuídas durante todo o ano, totalizando, em média, 1841 $\mathrm{mm}$ anuais. A altitude média da região é de $1017 \mathrm{~m}$ e o relevo caracteriza-se como ondulado. O solo é um Nitossolo Háplico típico.

Algumas características do perfil, descrito próximo ao local do experimento, encontram-se na Tabela 1. Para determinar a macroporosidade (Ma), microporosidade (Mi), porosidade total (Pt) e densidade do solo (Ds), foram coletadas amostras não deformadas, em anéis volumétricos com $5 \mathrm{~cm}$ de altura e $5 \mathrm{~cm}$ de diâmetro, enquanto para determinação de silte (Sil), argila (Arg) e areia (Are), coletaram-se amostras deformadas. A porosidade foi determinada com o uso da mesa de tensão; para os macroporos utilizou-se a altura de $60 \mathrm{~cm}$ de sucção, para os microporos, a altura de $100 \mathrm{~cm}$ de sucção e a porosidade total foi obtida pela soma de macro e microporos. A textura do solo foi determinada utilizando o Método Internacional da Pipeta (GEE \& BAUDER, 1986). A densidade do solo foi obtida pela razão entre o peso do solo seco a $105^{\circ} \mathrm{C}$ e o volume do anel no qual o solo foi coletado.

Dentro da área da parcela experimental, instalada na estrada, foram coletadas, em um único local, amostras do solo deformadas para determinar algumas características físicas e químicas do solo, cujos valores encontram-se na Tabela 2 .

A distribuição de tamanho e estabilidade dos agregados estáveis em água (DMP e DMG)

TABELA 1: Valores de macroporosidade (Ma), microporosidade (Mi), porosidade total (Pt), silte (Sil), argila (Arg), areia (Are) e densidade do solo (Ds), nos horizontes A e B do perfil do solo Nitossolo Háplico.

TABLE 1: Values of macroporosity (Ma), microporosity (Mi), total porosity (Pt), silt (Sil), clay (Arg), sand (Are) and soil density (Ds) in horizons A and B of 'Nitossolo Háplico'.

\begin{tabular}{|c|c|c|c|c|c|c|c|}
\hline Hor/Prof & $\mathrm{Ma}$ & Mi & $\mathrm{Pt}$ & Sil & Arg & Are & Ds \\
\hline $\mathrm{cm}$ & \multicolumn{6}{|c|}{-------------------------------- $\%$} & $\mathrm{~g} \mathrm{~cm}^{-3}$ \\
\hline A1 $(0-16)$ & 11 & 42 & 53 & 34 & 58 & 8 & 0,9 \\
\hline A2 $(16-38)$ & 9 & 46 & 55 & 33 & 60 & 7 & 1,2 \\
\hline $\mathrm{A} / \mathrm{B}(38-56)$ & 3 & 47 & 50 & 30 & 64 & 6 & 1,2 \\
\hline $\mathrm{B} / \mathrm{A}(56-82)$ & 5 & 50 & 55 & 22 & 73 & 5 & 1,2 \\
\hline B1 $(82-102)$ & 4 & 51 & 55 & 20 & 75 & 5 & 1,2 \\
\hline B2 $(102-140)$ & 1 & 53 & 54 & 21 & 74 & 5 & 1,2 \\
\hline
\end{tabular}


TABELA 2: Valores de diâmetros médios ponderado (DMP) e geométrico (DMG), matéria orgânica (MO), pH em água 1:1, alumínio trocável ( $\mathrm{Al})$, capacidade de troca de cátions (CTC), fósforo (P), potássio $(\mathrm{K})$, cálcio $(\mathrm{Ca})$, magnésio $(\mathrm{Mg})$, cobre $(\mathrm{Cu})$, zinco $(\mathrm{Zn})$, manganês $(\mathrm{Mn})$ e ferro $(\mathrm{Fe})$, da camada superficial do Nitossolo Háplico, na estrada estudada.

TABLE 2: Weighted average diameter values (DMP) and average geometric diameter values (DMG) organic material (MO), water $\mathrm{pH}$ 1:1, changeable aluminum (Al), capacity of cations exchange (CTC), phosphorus $(\mathrm{P})$, potassium $(\mathrm{K})$, calcium $(\mathrm{Ca})$, magnesium $(\mathrm{Mg})$, copper $(\mathrm{Cu})$, zinc $(\mathrm{Zn})$, manganese $(\mathrm{Mn})$ and iron $(\mathrm{Fe})$, of the superficial layer of 'Nitossolo Háplico'.

\begin{tabular}{|c|c|c|c|c|c|c|c|}
\hline Camada & DMP & DMG & MO & $\mathrm{pH}\left(\mathrm{H}_{2} \mathrm{O}\right)$ & & $\mathrm{Al}$ & СТC \\
\hline $\mathrm{cm}$ & \multicolumn{2}{|c|}{-------- mm ------- } & $\%$ & $1: 1$ & & \multicolumn{2}{|c|}{----- $\mathrm{cmol}_{\mathrm{c}} \mathrm{dm}^{-3}$----- } \\
\hline $0-5$ & 5,72 & 5,24 & 3,4 & 4,4 & & 4,9 & 6,4 \\
\hline $5-10$ & 3,89 & 2,87 & 3,1 & 4,3 & & 5,2 & 6,3 \\
\hline $10-15$ & 2,91 & 1,84 & 2,5 & 4,2 & & 4,1 & 5,0 \\
\hline $15-20$ & 2,96 & 1,88 & 2,7 & 4,2 & & 4,3 & 5,6 \\
\hline Camada & $\mathrm{P}$ & $\mathrm{K}$ (água-régia) & \multicolumn{2}{|c|}{ K (Melich) } & $\mathrm{Ca}$ & \multicolumn{2}{|c|}{$\mathrm{Mg}$} \\
\hline $\mathrm{cm}$ & \multicolumn{7}{|c|}{ 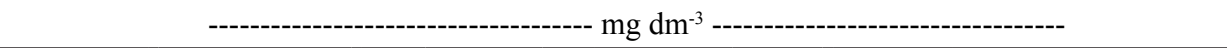 } \\
\hline $0-5$ & 3,6 & 414 & & & 1,04 & \multicolumn{2}{|c|}{0,39} \\
\hline $5-10$ & 2,5 & 454 & & & 0,74 & \multicolumn{2}{|c|}{0,32} \\
\hline $10-15$ & 1,8 & 305 & & & 0,68 & \multicolumn{2}{|c|}{0,25} \\
\hline $15-20$ & 3,6 & 283 & & & 0,99 & \multicolumn{2}{|c|}{0,31} \\
\hline Camada & \multicolumn{2}{|c|}{$\mathrm{Cu}$} & $\mathrm{Zn}$ & $\mathrm{Mn}$ & \multicolumn{3}{|c|}{$\mathrm{Fe}$} \\
\hline $\mathrm{cm}$ & \multicolumn{7}{|c|}{ - $\mathrm{mg} \mathrm{dm}^{-3}$} \\
\hline $0-5$ & \multicolumn{2}{|c|}{5,89} & 0,33 & \multicolumn{2}{|l|}{7,80} & \multicolumn{2}{|c|}{48.415} \\
\hline $5-10$ & \multicolumn{2}{|c|}{4,16} & 3,60 & \multicolumn{2}{|l|}{8,92} & \multicolumn{2}{|c|}{47.239} \\
\hline $10-15$ & \multicolumn{2}{|c|}{5,89} & 3,91 & \multicolumn{2}{|l|}{8,80} & \multicolumn{2}{|c|}{46.279} \\
\hline $15-20$ & \multicolumn{2}{|c|}{4,20} & 5,01 & \multicolumn{2}{|l|}{9,14} & \multicolumn{2}{|c|}{43.488} \\
\hline
\end{tabular}

foi feita pelo método de Kemper e Cheppil (1965). Para determinar matéria orgânica, $\mathrm{pH}$ em água, do alumínio trocável e capacidade de troca de cátions no solo seguiu-se a metodologia recomendada por Tedesco et al. (1995). Para determinação dos teores de potássio, cobre, ferro, zinco e manganês no solo, foi determinado digerindo-se as amostras em solução de água-régia para posterior diluição, conforme método descrito por Pierangeli (1999) e leitura no Espectrofotômetro de Absorção Atômica de alta resolução, de fonte contínua, com atomização através de chama ar-acetileno. $\mathrm{O}$ teor de fósforo, potássio, cálcio, magnésio e carbono orgânico, foi determinado nos sedimentos da erosão e no solo da parcela, pela metodologia recomendada por Tedesco et al. (1995). A determinação dos teores de ferro, cobre, zinco, manganês e potássio, semitotais, nas amostras de sedimentos, foi realizada por Espectrofotômetro de Absorção Atômica de alta resolução, de fonte contínua, com atomização através de chama ar-acetileno, após extração com água-régia (PIERANGELI, 1999), com modificações. Para obtenção dos teores de fósforo na água da enxurrada, o método usado foi de Murphy \& Riley (1962).

Um único tratamento, sem repetição, foi estudado. A unidade experimental, ou parcela, instalada na estrada apresentava $19 \mathrm{~m}$ de comprimento no sentido do declive e $4 \mathrm{~m}$ de largura, totalizando $76 \mathrm{~m}^{2}$ (Figura 1), com declividade média de $9,8 \%$.

$\mathrm{Na}$ instalação da parcela experimental, levou-se em consideração o nível do terreno, que havia sido rebaixado em $0,7 \mathrm{~m}$, devido à construção do leito da estrada e ao efeito da erosão em anos anteriores. Desse modo, a erosão hídrica quantificada e analisada, ocorrida no tratamento, era do topo da camada do solo referente ao horizonte B/A. Para instalação da parcela, procedeu-se do seguinte modo: drenos foram construídos na cabeceira e nas laterais da parcela, com o objetivo de isolar a área útil da mesma do restante da área da estrada. $\mathrm{Na}$ cabeceira, o isolamento foi melhorado com a colocação de uma prancha de madeira associada 


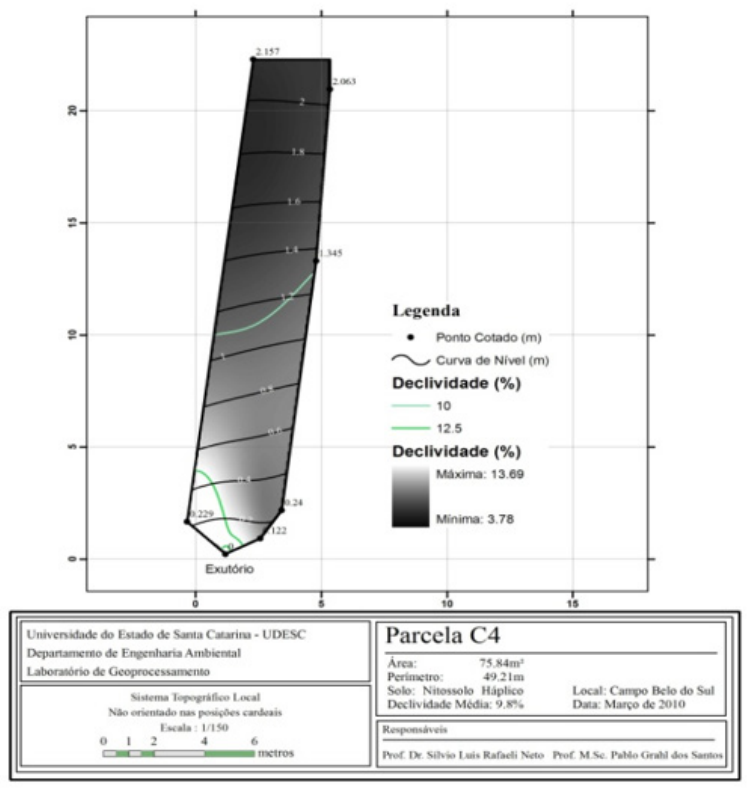

FIGURA 1: Desenho da parcela experimental delimitada na estrada. Fonte: Sílvio Rafaeli Neto.

FIGURE 1: Illustration of the delimited experimental road parcel. Source: Sílvio Rafaeli Neto.

ao dreno. Com isso, desviou-se o excedente de enxurrada que provinha da parte superior e dos barrancos da estrada e evitou-se que o escoamento superficial de dentro da parcela saísse da mesma. Para quantificar o volume de chuva no local do experimento, foi colocado um coletor a céu aberto (pluviômetro), distante $10 \mathrm{~m}$ do local da parcela e fora da floresta.

Para a coleta de água e sedimentos decorrentes do escoamento superficial, foi usado um equipamento denominado Roda Coshocton (Figura 2), colocado ao final da pendente da parcela experimental. A Roda foi conectada por meio de uma mangueira a um balde plástico com tampa, com capacidade para 60 litros de água. Este equipamento é constituído de uma calha coletora e de uma roda divisora de enxurrada, o qual foi desenvolvido pelo Departamento de Agricultura dos Estados Unidos (PARSON, 1954). O equipamento coleta aproximadamente $1 \%$ da enxurrada ocorrida na área e incidente sobre o conjunto calha e roda. Alguns cuidados são necessários com relação ao uso deste equipamento. A roda divisora de enxurrada é acionada por meio da impulsão causada pelo fluxo de água incidente sobre ela, rompendo a inércia da mesma. Para que a inércia da roda seja rompida pela ação da água, é necessário que a calha seja colocada de modo a apresentar um leve desnível para frente (em direção à roda) e para o lado esquerdo (olhando de traz em direção à roda). Além disso, é importante manter o equipamento com cobertura de tela, protegido da queda de objetos sobre a roda (folhas, galhos, etc.), e manter limpa a área ao seu redor, sem vegetação no entorno que possa interferir no funcionamento da roda. Por isso, é necessário constante monitoramento do ambiente no entorno da roda e do equipamento como um todo.

As perdas de água por escoamento superficial foram determinadas pelo valor da medição direta do volume coletado pela Roda Coshocton, multiplicado por 100. Para perda de solo, era realizada a coleta das amostras contendo a suspensão de água e sedimentos contida no balde e, após a retirada total da água, o peso seco dos sedimentos secos era também multiplicado por 100. A altura da lâmina de enxurrada contida dentro do balde coletor conectado à Roda Coshocton foi medida com o auxílio de uma régua de madeira graduada, com 1 metro de comprimento, colocada no centro do balde. Considerando que a altura e o diâmetro do balde eram conhecidos, tornou-se possível determinar o volume de enxurrada total contida no recipiente. $\mathrm{O}$ volume de água medida no balde igualmente foi extrapolado para a área total da parcela experimental e depois por hectare.

Os sedimentos contidos na enxurrada, depositados no leito da Roda Coshocton, foram coletados com espátula e acondicionados em balde previamente identificado. Em laboratório, o balde foi levado à estufa $60^{\circ} \mathrm{C}$ até a secagem. $\mathrm{O}$ valor da massa seca dos sedimentos obtidos na calha coletora foi somado ao valor da massa seca de sedimentos

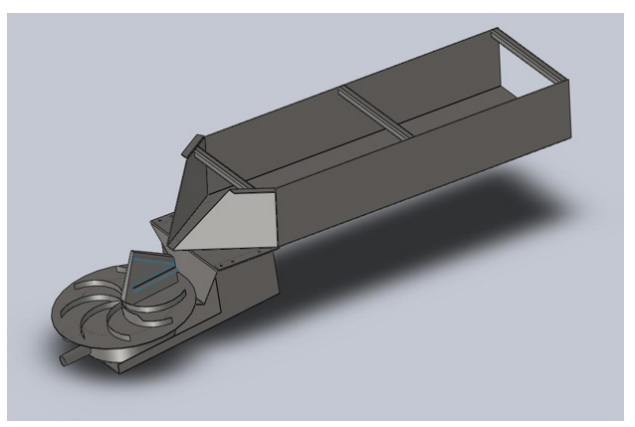

FIGURA 2: Desenho da Roda Coshocton. Fonte: Camilo Bertól.

FIGURE 2: Illustration of Coshocton wheel. Source: Camilo Bertól. 
na enxurrada e presentes no balde coletor. $\mathrm{O}$ valor do somatório de solo perdido foi extrapolado para a área total de cada parcela experimental.

A coleta de enxurrada foi realizada semanalmente, respeitando-se o final das precipitações acumuladas no período. Foram coletadas amostras de enxurrada para o cálculo das perdas de água e solo e para as análises químicas. As amostras foram obtidas do recipiente coletor de enxurrada após intensa agitação, a fim de homogeneizar a enxurrada. As amostras foram coletadas em frascos plásticos de $400 \mathrm{~mL}$, com 4 repetições. Ao chegarem ao laboratório, três frascos eram pesados e adicionavam-se três gotas de $\mathrm{HCl}$ 0,5 N, para acelerar a floculação e decantação dos sedimentos. Após 24 horas, a alíquota de água era retirada da amostra e o frasco com o restante de água e sedimentos era levado à estufa a $60^{\circ} \mathrm{C}$ até secagem. Os sedimentos restantes no fundo do frasco eram retirados com espátula e armazenados para posterior análise química. O quarto frasco coletado ficava sob refrigeração para posterior análise química para análise da água da enxurrada.

Previamente à determinação dos nutrientes na água da enxurrada, as amostras foram filtradas e uma alíquota de $20 \mathrm{~mL}$ de cada amostra foi acidificada com $0,5 \mathrm{~mL}$ de $\mathrm{HNO}_{3}$ concentrado. Essa alíquota foi armazenada fora de refrigeração, em potes plásticos lavados com solução limpeza de $\mathrm{HNO}_{3}$ a $3 \%$, até o término das leituras e foram determinadas também por Espectrofotômetro de Absorção Atômica de alta resolução, de fonte contínua, com atomização através de chama aracetileno.

\section{RESULTADOS E DISCUSSÃO}

A erosão hídrica sobre a estrada estudada acarretou elevadas perdas de solo durante o período experimental, totalizando $149,335 \mathrm{~kg}$ na parcela de $76 \mathrm{~m}^{2}$ (Tabela 3), equivalentes a $19,65 \mathrm{t} \mathrm{ha}^{-1}$, valor esse semelhante aos encontrados por Camargo Corrêa (2005) estudando erosão hídrica em estradas de uso florestal no município de Itaiópolis - SC, durante 15 meses. As perdas de solo foram ocasionadas por $1936 \mathrm{~mm}$ de chuva que produziram $716 \mathrm{~mm}$ de enxurrada, equivalente a $37 \%$ da precipitação total do período de estudo. Os valores de perda de solo variaram desde essencialmente zero até $10,001 \mathrm{~kg}$ na parcela, enquanto a enxurrada variou de zero a $53 \mathrm{~mm}$ e, a chuva, de zero a 159 $\mathrm{mm}$. Este comportamento é normal, pois, as perdas de água na forma de enxurrada são fortemente influenciadas pelo teor de água no solo antecedente à ocorrência das chuvas, enquanto as perdas de solo sofrem menos esse efeito, conforme cita Kohnke (1968).

Segundo Bertol e Almeida (2000), para o Nitossolo em questão, a tolerância de perda de solo é de $12 \mathrm{t} \mathrm{ha}^{-1}$ ano $^{-1}$, ou seja, pouco mais da metade do que foi perdido durante os meses avaliados. Esses números reforçam os cuidados que se deve ter na implantação e manutenção das redes viárias nos empreendimentos florestais, pois as estradas são as principais causadoras de enxurradas, quando comparadas aos demais usos do solo estudados.

As relações apresentadas na Figura 3, todas lineares e positivas, indicam valores de coeficiente de correlação relativamente baixos, porém, significativos. Na Figura $3 \mathrm{~A}$ que relaciona perda de água com altura de chuva, percebe-se que em muitos casos ocorreram elevadas perdas de água com alturas de chuva relativamente baixas, explicadas principalmente porque, em solo descoberto e compactado, como é o caso da estrada, a infiltração de água no solo é baixa. Além disso, é possível que essas chuvas tenham ocorrido sobre o solo já úmido por chuvas anteriores. No caso da relação das perdas de solo com altura de chuva, houve maior dispersão dos pontos na Figura 3B, significando que tanto chuvas de baixo volume ocasionaram elevadas perdas de solo, quanto chuvas de alto volume ocasionaram baixas perdas de solo. Nesse caso, o fator preponderante da variabilidade dos dados foi a variação no teor de água no solo antecedente às chuvas. $\mathrm{O}$ aumento de enxurrada ocasiona aumento nas perdas de solo, o que pode ser observado na Figura 3C. As perdas de solo relacionaram-se com as perdas de água, com maior coeficiente de correlação do que nas outras relações, evidenciando que o aumento na taxa de enxurrada se refletiu em aumento de energia de desagregação e transporte de sedimentos.

Os teores de fósforo $(\mathrm{P})$, potássio $(\mathrm{K})$, cálcio $(\mathrm{Ca})$ e magnésio $(\mathrm{Mg})$ presentes nos sedimentos da erosão, tanto nos retidos no balde de armazenagem quanto na calha coletora, foram maiores do que aqueles contidos na camada superficial do solo da qual a erosão se originou (Tabela 4), conforme verificado também por Seganfredo et al. (1997). No caso do fósforo, a razão foi de 1,25 para os sedimentos do balde e de 1,81 para os da calha. As razões foram respectivamente de 2 vezes e de 
TABELA 3: Valores de altura de chuva e enxurrada e de perdas de solo, obtidos em cada coleta na estrada, de setembro de 2009 a janeiro de 2011 no local do experimento.

TABLE 3: Rain, rainfall and soil loss values obtained in each road sample, from September 2009 to January 2011.

\begin{tabular}{|c|c|c|c|}
\hline \multirow{2}{*}{ Data da coleta } & Chuva & Enxurrada & Perda de solo \\
\hline & \multicolumn{2}{|c|}{ 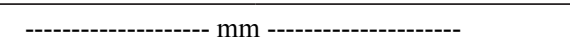 } & $\mathrm{kg}_{\text {parcela }}^{-1}$ \\
\hline 08/09/2009 & 102 & 42 & 6,375 \\
\hline $14 / 09 / 2009$ & 147 & 41 & 2,039 \\
\hline $21 / 09 / 2009$ & 28 & 28 & 2,566 \\
\hline $28 / 09 / 2009$ & 131 & 53 & 9,593 \\
\hline 05/10/2009 & 9 & 2 & 0,784 \\
\hline $14 / 10 / 2009$ & 55 & 36 & 4,512 \\
\hline $19 / 10 / 2009$ & 50 & 36 & 4,567 \\
\hline $23 / 10 / 2009$ & 2 & 0 & 0 \\
\hline 09/11/2009 & 52 & 29 & 4,726 \\
\hline $19 / 11 / 2009$ & 43 & 36 & 7,335 \\
\hline $26 / 11 / 2009$ & 39 & 33 & 7,236 \\
\hline $07 / 12 / 2009$ & 25 & 12 & 6,898 \\
\hline $21 / 12 / 2009$ & 34 & 16 & 8,296 \\
\hline $30 / 12 / 2009$ & 32 & 25 & 6,947 \\
\hline $06 / 01 / 2010$ & 69 & 36 & 9,110 \\
\hline $18 / 01 / 2010$ & 95 & 53 & 8,945 \\
\hline $22 / 01 / 2010$ & 47 & 21 & 4,971 \\
\hline $27 / 01 / 2010$ & 34 & 23 & 5,044 \\
\hline $01 / 02 / 2010$ & 0 & 0 & 0,192 \\
\hline $12 / 02 / 2010$ & 74 & 53 & 10,001 \\
\hline $18 / 02 / 2010$ & 103 & 35 & 3,326 \\
\hline $25 / 02 / 2010$ & 2 & 1 & 1,307 \\
\hline $01 / 03 / 2010$ & 0 & 0 & 0 \\
\hline $11 / 03 / 2010$ & 32 & 23 & 7,081 \\
\hline $22 / 03 / 2010$ & 19 & 14 & 2,024 \\
\hline $25 / 03 / 2010$ & 17 & 5 & 0,304 \\
\hline $08 / 04 / 2010$ & 0 & 0 & 0 \\
\hline $29 / 04 / 2010$ & 159 & 3 & 8,015 \\
\hline $10 / 05 / 2010$ & 53 & 1 & 1,799 \\
\hline $07 / 06 / 2010$ & 93 & 1 & 1,035 \\
\hline $22 / 06 / 2010$ & 72 & 53 & 6,013 \\
\hline $26 / 07 / 2010$ & 128 & 1 & 0,822 \\
\hline $18 / 08 / 2010$ & 49 & 1 & 2,499 \\
\hline $14 / 09 / 2010$ & 18 & 1 & 0,300 \\
\hline $24 / 09 / 2010$ & 123 & 2 & 4,673 \\
\hline Total & 1.936 & $716=37 \%$ da chuva & $149,34=19,65 \mathrm{tha}^{-1}$ \\
\hline
\end{tabular}

2,2 vezes, enquanto para o $\mathrm{Ca}$ e $\mathrm{Mg}$, as razões foram respectivamente de 1,2 e 1,4 vezes e de 1,5 e 1,9 vezes. Isso indica claramente que a erosão ocorrida na estrada em questão apresentou elevado potencial de enriquecimento em locais nos quais se depositou fora da estrada, em relação aos elementos anteriormente discutidos, conforme verificado também por Schick et al. (2000). Provavelmente, isto é devido à textura do material transportado, o qual é mais rico em silte e argila do que o solo do qual se originaram os sedimentos, uma vez que estas partículas são mais facilmente transportadas e contêm maiores teores de nutrientes adsorvidos, conforme demonstraram Freitas e Castro (1983). 

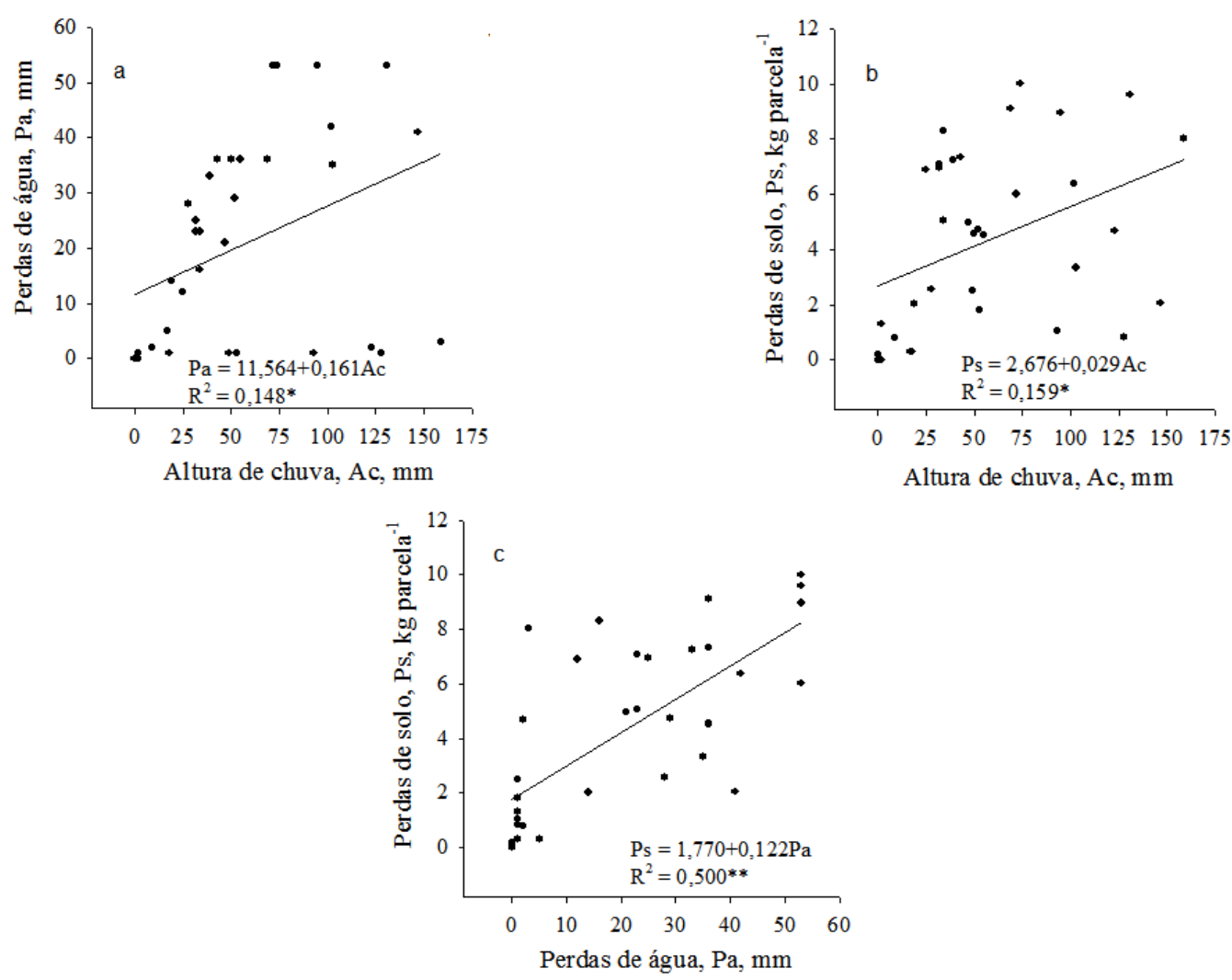

FIGURA 3: Relação de perda de água (Pa) com altura de chuva (Ac), perda de solo (Ps) com altura de chuva (Ac) e perda de solo (Ps) com perda de água (Pa).*Significativo a 5\%.

FIGURE 3: Relation among water lost (Pa) with rain height (Ac), soil lost (Ps) with rain height (Ac) and soil lost (Ps) with water lost (Pa). *Significant at $5 \%$.

De modo geral, o cálcio e magnésio são perdidos em grandes quantidades nos sedimentos da erosão (CASTRO et al., 1983; DEDECECK et al., 1986; BERTOL, 1994), especialmente o cálcio que está adsorvido aos coloides do solo, o que facilita o seu transporte nos sedimentos.

Para o caso dos elementos zinco (Zn) e manganês (Mn), também os teores contidos nos sedimentos, sejam eles no balde ou na calha, foram maiores do que os contidos na camada superficial do solo, gerando uma taxa de enriquecimento importante, o que não ocorreu com o cobre $(\mathrm{Cu})$ e o ferro $(\mathrm{Fe})$ (Tabela 5).

No caso do zinco, a taxa de enriquecimento gerada pelo teor do elemento nos sedimentos do balde foi 11, enquanto para os sedimentos da calha foi de 22 em relação ao teor no solo (Tabela 5). Para o manganês, as referidas taxas foram respectivamente de $40 \%$ e de $55 \%$. Assim, especialmente o zinco apresentou um elevadíssimo poder de contaminação do ambiente em que o material da erosão se depositou, fora da estrada, não se desprezando também o potencial do manganês.

Schick et al. (2000), analisando água de enxurrada, quantificaram maiores teores de potássio do que de fósforo. Segundo os autores, isso ocorre em razão da maior solubilidade deste elemento, em relação ao fósforo, o que facilita seu transporte pela água e também porque está presente em maior quantidade no solo do que o fósforo. Os teores de macro e micronutrientes encontradas na água da enxurrada foram baixos em relação aos contidos no solo e nos sedimentos (Tabela 6). Assim, as perdas destes elementos por erosão estão mais relacionadas com os sedimentos, por estarem nestes adsorvidos do que na água da enxurrada, devido à baixa solubilidade desses elementos.

No caso do cálcio, magnésio, potássio e fósforo, a relação dos teores no solo para a água foi respectivamente de $27 ; 36 ; 314$; e 212 , enquanto para cobre, zinco, manganês e ferro, a relação foi respectivamente de $5.900 ; 34 ; 3.714$; e 353.652 (Tabela 6).

Considerando as perdas totais dos macro 
TABELA 4: Teores de P, K, Ca e Mg, na camada do de $0-5 \mathrm{~cm}$ do solo da parcela e nos sedimentos contidos no balde e na calha, determinados sob diferentes métodos de extração, durante o período de setembro de 2009 a janeiro de 2011.

TABLE 4: $\mathrm{P}, \mathrm{K}, \mathrm{Ca}$ and $\mathrm{Mg}$ contents in $0-5 \mathrm{~cm}$ layer of the soil parcel and in sediments from the bucket and trough, determined by different extraction methods, from September 2009 to January 2011.

\begin{tabular}{|c|c|c|c|c|}
\hline $\mathrm{P}$ (Melich) & $\mathrm{K}$ (água-régia) & K (Melich) & $\mathrm{Ca}(\mathrm{KCl})$ & $\mathrm{Mg}(\mathrm{KCl})$ \\
\hline \multicolumn{5}{|c|}{ - } \\
\hline \multicolumn{5}{|c|}{ No solo da parcela } \\
\hline 3,6 & 414 & 29 & 68 & 47 \\
\hline \multicolumn{5}{|c|}{ Nos sedimentos do balde } \\
\hline 4,5 & 426 & 58 & 80 & 72 \\
\hline \multicolumn{5}{|c|}{ Nos sedimentos da calha } \\
\hline 6,5 & 559 & 63 & 96 & 88 \\
\hline
\end{tabular}

TABELA 5: Teores de $\mathrm{Cu}, \mathrm{Zn}, \mathrm{Mn}$ e Fe, contidos na camada de $0-5 \mathrm{~cm}$ do solo da parcela e nos sedimentos contidos no balde e na calha, determinados pelo método de extração em água-régia, durante o período de setembro de 2009 a janeiro de 2011.

TABLE 5: $\mathrm{Cu}, \mathrm{Zn}, \mathrm{Mn}$ and $\mathrm{Fe}$ contents in $0-5 \mathrm{~cm}$ layer of the soil parcel and in sediments from the bucket and trough, determined by extraction method with acquaregia, from September 2009 to January 2011.

\begin{tabular}{|c|c|c|c|}
\hline $\mathrm{Cu}$ & $\mathrm{Zn}$ & $\mathrm{Mn}$ & $\mathrm{Fe}$ \\
\hline \multicolumn{4}{|c|}{ - } \\
\hline \multicolumn{4}{|c|}{ No solo da parcela } \\
\hline 5,9 & 0,3 & 7,8 & 48.415 \\
\hline \multicolumn{4}{|c|}{ Nos sedimentos do balde } \\
\hline 3,8 & 3,3 & 10,9 & 50.085 \\
\hline \multicolumn{4}{|c|}{ Nos sedimentos da calha } \\
\hline 5,9 & 6,6 & 12,1 & 47.453 \\
\hline
\end{tabular}

TABELA 6: Teores de alguns macronutrientes e micronutrientes contidos na camada de $0-5 \mathrm{~cm}$ do solo da parcela e na água da enxurrada, durante o período de setembro de 2009 a janeiro de 2011.

TABLE 6: Content of some macronutrients in $0-5 \mathrm{~cm}$ layer of the soil parcel and runoff, from September 2009 to January 2011.

\begin{tabular}{|c|c|c|c|}
\hline $\mathrm{P}$ & $\mathrm{K}$ & $\mathrm{Ca}$ & $\mathrm{Mg}$ \\
\hline \multicolumn{4}{|c|}{ No solo da parcela $\left(\mathrm{mg} \mathrm{dm}^{-3}\right)$} \\
\hline 3,6 & 29 & 68 & 347 \\
\hline \multicolumn{4}{|c|}{$\mathrm{Na}$ água da enxurrada $\left(\mathrm{mg} \mathrm{L}^{-1}\right)$} \\
\hline 2,50 & 1,30 & 0,92 & 0,017 \\
\hline $\mathrm{Cu}$ & $\mathrm{Zn}$ & $\mathrm{Mn}$ & $\mathrm{Fe}$ \\
\hline \multicolumn{4}{|c|}{ No solo da parcela $\left(\mathrm{mg} \mathrm{dm}^{-3}\right)$} \\
\hline 5,9 & 0,3 & 7,8 & 48.415 \\
\hline \multicolumn{4}{|c|}{$\mathrm{Na}$ água da enxurrada $\left(\mathrm{mg} \mathrm{L}^{-1}\right)$} \\
\hline 0,0010 & 0,0089 & 0,0021 & 0,1369 \\
\hline
\end{tabular}


TABELA 7: Quantidades perdidas de alguns macronutrientes e micronutrientes nos sedimentos e na água da enxurrada, durante o período de setembro de 2009 a janeiro de 2011.

TABLE 7: Lost quantities of some macro and micronutrients in sediments and runoff, from September 2009 to January 2011.

\begin{tabular}{|c|c|c|c|}
\hline \multicolumn{4}{|c|}{ - } \\
\hline \multicolumn{4}{|c|}{ Nos sedimentos } \\
\hline$P$ & $\mathrm{~K}$ & $\mathrm{Ca}$ & $\mathrm{Mg}$ \\
\hline 0,24 & 12,84 & 7,30 & 2,69 \\
\hline $\mathrm{Fe}$ & $\mathrm{Mn}$ & $\mathrm{Cu}$ & $\mathrm{Zn}$ \\
\hline 2.143 & 0,24 & 0,21 & 0,22 \\
\hline \multicolumn{4}{|c|}{$\mathrm{Na}$ água da enxurrada } \\
\hline $\mathrm{P}$ & $\mathrm{K}$ & $\mathrm{Ca}$ & $\mathrm{Mg}$ \\
\hline 0,16 & 8,56 & 23,19 & 0,29 \\
\hline $\mathrm{Fe}$ & $\mathrm{Mn}$ & $\mathrm{Cu}$ & $\mathrm{Zn}$ \\
\hline 1,271 & 0,019 & 0,009 & 0,083 \\
\hline
\end{tabular}

e micronutrientes estudados, adsorvidos aos sedimentos e solúveis na água da enxurrada (Tabela 7), verifica-se que a erosão produzida na estrada estudada transportou $30,49 \mathrm{~kg} \mathrm{ha}^{-1}$ de cálcio; 2,98 $\mathrm{kg} \mathrm{ha}^{-1}$ de magnésio; $21,40 \mathrm{~kg} \mathrm{ha}^{-1}$ de potássio; 0,40 $\mathrm{kg} \mathrm{ha}^{-1}$ de fósforo; $0,22 \mathrm{~kg} \mathrm{ha}^{-1}$ de cobre; $0,30 \mathrm{~kg} \mathrm{ha}^{-1}$ de zinco; $0,26 \mathrm{~kg} \mathrm{ha}^{-1}$ de manganês; e $2.145 \mathrm{~kg} \mathrm{ha}^{-1}$ de ferro total. Esses dados reforçam a necessidade de cuidados na implantação e manutenção das redes viárias nos empreendimentos, pois as estradas são as principais causadoras de enxurradas, quando comparadas aos demais usos do solo estudados.

\section{CONCLUSÕES}

As perdas de solo na estrada de uso florestal foram de 19,65 $\mathrm{t} \mathrm{ha}^{-1}$, enquanto as perdas de água equivaleram a $37 \%$ do volume de chuva precipitado no período experimental.

Houve correlação linear e positiva entre altura de chuva e perdas de água por escoamento superficial, entre altura de chuva e perdas de solo por erosão, e entre perdas de solo e de água por erosão hídrica, na estrada de uso florestal estudada.

Os teores dos elementos químicos estudados em geral foram altos nos sedimentos da erosão hídrica, superiores aos teores encontrados na camada superficial do solo da qual a erosão se originou e muito superiores aos encontrados na água da enxurrada.

\section{REFERÊNCIAS BIBLIOGRÁFICAS}

BERTOL, I. Perdas de nutrientes por erosão hídrica em diferentes sistemas de manejo de solo sob rotação de culturas. Univ. \& Des., v. 2, p. 174 - 184, 1994 (Boletim Técnico).

BERTOL, I.; ALMEIDA, J. A. Tolerância de perda de solo por erosão para os principais solos do estado de Santa Catarina. Revista Brasileira de Ciência do Solo, Viçosa, v. 24, n. 3, p. 657-668, 2000.

CAMARGO CORRÊA, C. M.; DEDECECK, R. A. Erosão real e estimada através da rusle em estradas de uso florestais, em condições de relevo plano a suave ondulado. Floresta, Curitiba, v. 39, n. 2, p. 381-391, 2009.

CAMARGO CORREAA, C. M. Perdas de solo e a qualidade da água procedente de estrada de uso florestal no planalto catarinense. 2005.155 p. Tese (Doutorado em Ciências Florestais). Universidade Federal do Paraná. Curitiba. Paraná. 2005.

CASTRO, P. S. Interceptação da chuva por mata natural secundária na região de Viçosa, MG. Revista Árvore, Viçosa, v. 7, n. 1, p. 76-89, 1983.

CAVICHIOLO, S. R. Perdas de solo e nutrientes por erosão hídrica em diferentes métodos de preparo do solo em plantio de Pinus taeda. 2005. 152 p.Tese (Doutorado em Ciências Florestais) - Programa de Pós Graduação em Engenharia Florestal. Universidade Federal do Paraná. 2005.

CHRISTOPHER Jr., E. A. Post harvesting evaluation of best management practices for the prevention of soil erosion in Virginia. 2002. 125 p. 
Master of Science in Forestry. Virginia Polytechnic Instituteand State University, Blacksburg, 2002.

DEDECEK, R. A.; RESK, D. V. S.; FREITAS Jr. E. Perdas de solo, água e nutrientes por erosão em Latossolo Vermelho-Escuro dos cerrados em diferentes cultivos sob chuva natural. Revista Brasileira de Ciência do Solo, Viçosa, v.10, p. 265-272, 1986.

FREITAS, P. L.; CASTRO, A. F. Estimativas das perdas de solo e nutrientes por erosão no Estado do Paraná. Boletim Informativo, SBCS, v. 8, p. 43-52, 1983.

GEE, G. W.; BAUDER, J. W. Particle-size analysis. In: KLUTE, A. Methods of soil analysis. American Society of Agronomy, 1: 383-411. 1986.

KEMPER, W. D.; CHEPIL, W. S. Size distribution of aggregates. In: BLACK, C. A.; EVANS, D. D.; WHITE, J. L.; ENSMINGER, L. E. ; CLARCK, F. E., eds. Methods of soil analysis. Part 1, Madison: American Society of Agronomy, 1965. p. 499-510. KOPPEN, W. Climatologia: Um studio do los climas de la tierra. Fondo del Cultura Economica, Mexico. 1948. 478 p.

MURPHY, J.; RILEY, J. P. A modified single solution method for determination of phosphate in natural waters. Anal. Chem. Acta, v. 26, p. 31-36, 1962.

NEARY, D. G.; HORNBECK, J. W. Impacts of harvesting and associated practices on offsite environmental quality. In:
Impacts of forest harvesting on long-term site productivity.Londres: Chapman and Hall, 1994. cap.4, p.81-119.

PARSONS, D. A. Coshocton - Type runoff samplers. Washington, DC: Laboratory investigations. United States Departament of Agriculture. Soil Conservation Service, 1954. 16 p. PIERANGELI, M. A. P. Chumbo em latossolos brasileiros: adsorção e dessorção sob efeito de $\mathrm{pH}$ e força iônica. 1999. 108 p. Dissertação (Mestrado em Solos e Nutrição de Plantas) Programa de Pós Gradação em Agronomia, Universidade Federal de Lavras, 1999.

SCHICK, J.et al. Erosão hídrica em cambissolo húmico alumínico submetido a diferentes sistemas de preparo e cultivo do solo: II. Perdas de nutrientes e carbono orgânico. Revista Brasileira de Ciência do Solo, Viçosa, v. 24, p. 437-447, 2000.

SEGANFREDO, M. L.; ELTZ, F. L. F.; BRUM, A. C. R. Perdas de solo, água e nutrientes por erosão em sistemas de culturas em plantio direto. Revista Brasileira de Ciência do Solo, Viçosa, v. 21, p. 287-291, 1997.

SOUZA, C. R.; SEIXAS, F. Avaliação de diferentes coberturas do solo no controle da erosão em taludes de estradas florestais. Scientia Forestalis, Piracicaba, , n. 60, p. 45-51, 2001.

TEDESCO, J. M. Nitrogênio. In: GIANELLO, C.; BISSANI, C. A.; TEDESCO, J. M. Princípios de Fertilidade do Solo. Porto Alegre: Departamento de Solos da UFRGS, 1995. 174 p. 